\title{
DIGITALISING INDIGENOUS LANGUAGES: PRODUCTIVITY, ACCESSIBILITY AND MOBILITY IN THE GLOBAL SOUTH
}

\author{
Hambaba Jimaima \\ LASU President \\ b.jamaima@unza.zm
}

In the broader context of digitalisation and electronically medicated discourse predicated on globalisation, the question of inclusivity and accessibility re-awakens discussions on digitalising indigenous languages especially in the diglossic and multilingual languages of Africa. Over the past decades, in particular, in discussions that have energised LASU conferences, the role of indigenous languages in development, their production and uptake has remained central. In this Special Issue of the Journal of Law and Special Sciences, which conflicts the $15^{\text {th }} \mathbf{L A S U}$ conference theorisation, the call to digitalise the indigenous languages is part of a scholarly invitation to (re)propose ways in which indigenous languages can be part of the global semiotic flows and resources amenable to production, accessibility and mobility beyond the linguistic virtual-scape of the Global South. The evident permeable boundaries - linguistic and national - force us to prioritise digitising indigenous languages, as this process relates to electronic language documentation, description and electronic languages production, and consumption for preservation and day-to-day use. 